\title{
Enciclopedismo, distinção profissional e modernidade nas ciências matemáticas brasileiras (1808-1930 $)^{1}$
}

\section{Encyclopedism, professional distinction and modernity in Brazilian mathematical sciences (1808-1930)}

\section{ROGÉRIO MONTEIRO DE SIQUEIRA}

Universidade de São Paulo | USP

\begin{abstract}
RESUMO Após retrospecto sobre a recente historiografia das ciências matemáticas que se ocupa das práticas matemáticas no Brasil do século XIX e começo do XX, argumentamos que há pelo menos dois momentos distintos no período. No começo do século XIX, as práticas matemáticas estão fortemente ligadas a uma espécie de ilustração brasileira, onde as matemáticas compõem com a medicina, as letras, e as engenharias uma constelação de saberes inseparáveis, o que se costuma chamar de enciclopedismo. Aqui, a matemática é artigo de distinção social da elite ilustrada. No final do período, não mais instrumento dessa elite, vê-se as ciências matemáticas sendo objeto de distinção profissional: ora elas são acessórios das práticas de engenharia, ora são convocadas como objetos autônomos e desinteressados por parte de engenheiros-cientistas.
\end{abstract}

Palavras-chave historiografia da matemática - ciências matemáticas no Brasil - ilustração brasileira modernidade.

\begin{abstract}
After a survey of the recent historiography on mathematical sciences dealing with mathematical practices along the 19th and early 20th centuries in Brazil, we suggest at least two distinct movements in the period. In the beginning of the 19th century mathematical practices are strongly related to a kind of Brazilian enlightenment, where medicine, literature, and engineering constitute a constellation of amalgamated knowledge usually denoted as encyclopedic. At this point, mathematics is an item of social distinction for an enlightened elite. At the end of the period, not an elite instrument anymore, mathematical sciences are an object of professional distinction: Sometimes they are tools for engineering practices, sometimes they are claimed as autonomous and disinterested objects by scientist-engineers.
\end{abstract}

Key words historiography of mathematics - mathematical sciences in Brazil - brazilian enlightenment - modernity.

\section{Introdução}

Entre 1919 e 1923, Manoel Amoroso Costa (1885-1928) dedicou uma série de artigos de divulgação científica no carioca 0 Jornal a temas típicos da matemática moderna: geometrias não-euclidianas, lógica e fundamentos da matemática. Dentre as intenções de Amoroso estava a defesa perante um público leigo das práticas das ciências puras em território brasileiro². Em seu artigo "Pela ciência pura", em tom solene e irônico, ele dirá: "o nosso terreno é ainda impróprio ao cultivo dessa suprema flor de espírito, que é a ciência pura, contemplativa e desinteressada"3.

Os textos de Amoroso têm servido de mote para uma determinada historiografia das ciências brasileiras discutir a falta de uma tradição científica no Brasil. Seria o Brasil dado ou não às práticas científicas e às ciências puras? 
A questão perpassa muitos textos conhecidos e amplamente debatidos ${ }^{4}$. No que tange à matemática, os primeiros a que temos notícia são "A matemática no Brasil" de Francisco Mendes de Oliveira Castro (1902-1993), publicado no grande volume As ciências no Brasil por Fernando de Azevedo em 1955, e "Ciências Matemáticas" de Chaim Samuel Hönig (1926-) e Elza Gomide (1925-), publicado na História das Ciências no Brasil, organizada por Shozo Motoyama e Mario Guimarães Ferri em 19795.

Comentando a questão da inabilidade brasileira em produzir matemática, os autores sugerem que "os progressos realizados pela matemática no século anterior [o XIX] ainda não haviam penetrado suficientemente no país"6 e que "o isolamento científico perdurava, e a pouca pesquisa produzida era fruto de autodidatismo"7. Enquanto que no caso de Amoroso, a questão está mais para um diagnóstico de um agente insatisfeito com os limites que o espaço social de então impunha às suas aspirações e a de toda uma geração de intelectuais ${ }^{8}$, a tese aqui tem ares de memória compartilhada pelas primeiras gerações de matemáticos brasileiros, história que dá sentido a uma comunidade que se consolidou com o advento das universidades nos anos 30, que conquistou certa autonomia de discurso e se diferenciou de outras duas categorias profissionais, os físicos e os engenheiros. Teria sido revolucionária a experiência dos anos trinta para as ciências matemáticas no país. A história anterior seria "pré-história", para usar os próprios termos de Chaim Samuel Hönig e Elza Gomide9

Mais tarde, a partir dos anos 90, com os primeiros doutorados em história da matemática no Brasil, a questão parece ser o principal tema debatido pela comunidade de historiadores em nascimento ${ }^{10}$. Nesse momento, é um observador privilegiado da comunidade de matemáticos brasileiros quem fala, cuja formação inicial na maioria dos casos se deu nas matemáticas, mas que reconverteu suas habilidades profissionais: do "fazer matemática" para o "fazer história". Embora haja um esforço da parte desses autores em compreender o século XIX em seus próprios termos, 0 foco ainda é nas rupturas e em um suposto isolamento protagonizado por poucas figuras que dispenderam suas energias militando contra uma comunidade avessa às ciências puras e desinteressadas. Para Silva,

até 1930, a matemática desenvolvia-se timidamente no país, graças aos esforços isolados de autodidatas. Algumas mentes brilhantes começaram a despontar, quase como num processo de seleção natural. A maioria dos que vamos mencionar obteve a sua formação acadêmica em escolas politécnicas e não em faculdades especializadas de matemática, que só começaram a surgir a partir dos anos $30^{11}$.

Aos poucos, vão surgindo na historiografia os heróis das ciências matemáticas brasileiras: Joaquim Gomes de Souza (1829-1864), Otto de Alencar Silva (1874-1912), Manuel de Amoroso Costa (1885-1928), Theodoro Augusto Ramos (1895-1935) e Lélio Itapuambyra Gama (1892-1891).

Joaquim Gomes de Souza (1829-1864), o mais antigo entre esses personagens, já havia sido "resgatado" com seu trabalho por Otto de Alencar e Amoroso Costal. Mais recentemente, Ubiratan D'Ambrosio escreveria que "Souzinha representava o pensamento oposto ao positivismo e é compreensível que tenha sido marginalizado no desenvolvimento da matemática positivista na segunda metade do século XIX"12.

Em 1898, Otto de Alencar escreverá o artigo "Alguns erros de Mathematica na Synthese Subjectiva de A. Comte" na Revista da Escola Polytecnica do Rio de Janeiro, artigo considerado por Pereira da Silva como

um precioso momento na história da ciência brasileira, um ponto de inflexão na curva ascendente da nefasta influência do positivismo no Brasil, porque contém as primeiras críticas, procedentes, a trabalhos científicos (matemáticos) de Comte feitas por um brasileiro que se dedicava às ciências ${ }^{13}$.

É por meio de Alencar, segundo Castro, que os alunos da Escola Polytechnica do Rio de Janeiro, entre eles Amoroso Costa, Theodoro Ramos e Lélio Gama, entrarão em contato com "os livros de Clebsh, Salmon, Koenigs e Darboux, [...] de Hermite, Jordan e Picard", além do "cálculo das probabilidades e os livros de physica mathematica de Poincaré" 14 . 
Mas serão Lélio Gama, no Rio de Janeiro, e Theodoro Ramos, em São Paulo, que, dez anos mais tarde, conseguirão testemunhar a criação de um espaço institucionalizado nas Universidades de São Paulo e do Brasil, condizente com o gosto do grupo, um espaço para a ciência "pura, contemplativa e desinteressada".

É bastante provável que a tese recente bebe nos discursos dos primeiros vinte anos do século XX, quando a defesa das ciências puras, a demanda por universidades e 0 ensino das ciências nas escolas foram bandeiras comuns entre os cientistas. ${ }^{16}$ Com essa geração também nascia a Academia Brasileira de Ciências (ABC) e um conjunto de novas revistas destinadas a um público especializado, também certa militância desse mesmo grupo na Academia Brasileira de Educação (ABE) para que 0 ensino básico passasse a conter disciplinas mais científicas ${ }^{17}$.

A insistência nas grandes rupturas, na construção de personagens isolados, na procura de indícios modernos nos textos de engenharia e ciências exatas, bem como uma frustração implícita nos textos de história da matemática no Brasil por não haver ciência no século XIX, a meu ver, está bastante comprometida com os vencedores dos anos 30 . As categorias de análise implicadas na representação histórica aproximaram aqueles que estavam distantes, quando tomaram como pais fundadores das novas práticas engenheiros que não praticavam as matemáticas dessa maneira moderna, por outro lado tornaram distantes das práticas de engenharia correntes no final do XIX aqueles que pleiteavam as ciências puras.

É certo que houve mudanças: uma diferenciação nas práticas e o aparecimento de novos critérios de julgamento entre engenheiros. Embora cada vez mais interessados em teoremas e teorias despregados de questões práticas, esses engenheiros ainda usavam da expertise técnica obtidas nas aulas de hidráulica e resistência dos materiais, para se tomar um exemplo, para decidir politicamente os processos de modernização pelos quais passavam o Rio de Janeiro e São Paulo na Primeira República. E é justamente esse capital político angariado no trabalho como engenheiro que vai ser mobilizado, mais tarde, na criação de um espaço social propício ao desinteresse, os departamentos de matemática e física nas novas universidades dos anos 30.

\section{Matemáticas mistas e enciclopedismo}

Os estudos das ciências matemáticas no Brasil, até o final da Primeira República, estão fundamentalmente ligados às escolas de engenharia. A Academia Real Militar, possivelmente a instituição mais conhecida das ciências matemáticas no XIX, foi fundada em 1810 com a vinda da família real portuguesa que chegava ao Brasil fugindo da invasão napoleônica em Portugal ${ }^{18}$.

Alguns estudos sobre a intelectualidade no período monárquico, especialmente na primeira metade do século XIX, nos levam a crer que o período estava bastante a favor das matemáticas e das ciências. Ao tratar da ilustração brasileira no começo do XIX, Maria Odila Dias observou que dos 55 deputados da assembleia que se ocuparam da constituinte no início do Primeiro Reinado, logo após a independência do Brasil de Portugal, 34 eram formados em ciências (12 em matemática e filosofia natural; 9 em matemática; 5 em filosofia natural; 3 em medicina e matemática e 2 simultaneamente em matemática, filosofia e medicina), enquanto que 21 se diplomaram em direito. Sendo assim, 26 deputados, ou seja, quase a metade deles, eram formados em matemática ${ }^{19}$.

Analisando dados sobre os formandos após a reforma pombalina da Universidade de Coimbra, Dias ${ }^{20}$ chega também a observações importantes sobre o gosto científico da elite brasileira no final do XVIII: nos vinte anos após a reforma, 430 brasileiros se formaram em ciências, e apenas 262 em humanidades, sobretudo direito. Trata-se, portanto, de uma elite interessada em ciências, uma ilustração brasileira, que seguramente valorizava os estudos de matemática como cultura geral. Um fenômeno similar àquele observado por Jean Dhombres ${ }^{21}$ na França do final do XVIII, embora ele não se materialize numa alta produção de livros de ciências, como foi o caso francês. Entre os mais de 1400 títulos editados pela Impressão Régia no Brasil entre 1808-822, que incluem livros, panfletos, manifestos e outros pequenos textos, não mais do que 21 livros tratavam 
das ciências matemáticas, aos moldes da llustração francesa (Geometria, 1 livro; Trigonometria, 2; Aritmética, 1; Física, 2; Álgebra, 4; Cálculo, 1; Mecânica, 4; Ótica, 1; Fortificação e Balística, 1; Astronomia e Geodesia, 3; Desenho, 1222.

0 domínio das letras, da língua estrangeira e da escrita é uma característica fundamental dessa geração de escritores. Como mostra a carta de Manuel Ferreira de Araújo Guimarães (1777-1838), um dos autores mais prolíficos em matemática no período ${ }^{23}$, ao ministro da guerra D. João de Melo Castro, a progressão na hierarquia do exército e o aumento de salários para os professores da Academia estava bastante ligada a capacidade de traduzir e escrever novos tratados. E é essa mesma habilidade que será empregada por Guimarães e também por José Saturnino da Costa Pereira, o tradutor de Lacroix, na edição de jornais do Rio de Janeiro. Além dos livros de ciências, Guimarães escreveu poesias em homenagem ao imperador D. João, e editou os jornais 0 Patriota (1813-1814), a Gazeta do Rio de Janeiro (1813-1821, 1826-1830) e 0 Espelho (1822), periódico a favor da independência do Brasil.

Nesse sentido, a trajetória de Joaquim Gomes de Souza, uma das figuras do século XIX mais lembradas pela historiografia da matemática brasileira, não teria nada de atribulada, ao contrário, seria exemplar do enciclopedismo do período. 0 autor de "Dissertação sobre o modo de indagar novos astros sem auxílio das observações directas", cursou engenharia por um ano na Academia, a partir de 1843, interrompeu o curso e ingressou na faculdade de medicina em 1845, abandonando-a no ano seguinte, formou-se em engenharia em 1848. Gomes de Souza torna-se deputado em 1857, obtém o título de médico da Faculdade de Medicina de Paris em 1858, e, no ano seguinte, organiza uma antologia "das melhores poesias líricas de diversas nações" em Leipzig. No mesmo período em que estuda medicina em Paris, submete alguns trabalhos de matemática à Académie des Sciences de Paris²4.

Esses dois exemplos, que não me parecem isolados ${ }^{25}$, transitam muito facilmente entre as artes científicas, literárias e políticas, disposição típica da mentalidade ilustrada brasileira na primeira metade do XIX. Faz pouco sentido, portanto, em falar em matemática como conhecimento autônomo, distinto dos outros saberes novecentistas no Brasil.

É também nesse contexto que o currículo da Academia Real Militar deve ser visto. Tratava-se de um currículo essencialmente de ciências matemáticas puras e mistas, onde as questões militares, a filosofia natural e as artes morais ocupavam pouco espaço. 0 currículo estava organizado em sete anos. Nos quatro primeiros eram ensinadas as matemáticas até o cálculo diferencial e integral, depois a física e balística e, no final, trigonometria esférica, ótica, e cartografia. Os três últimos anos eram dedicados às artes militares, química, fortificação e história natural. Para se formar engenheiro ou na artilharia, era preciso estudar todos os sete anos. Somente os integrantes da cavalaria ou infantaria estudavam o primeiro ano da parte matemática e da parte militar.

\section{Diferenciação profissional e declínio das ciências exatas?}

Essa organização recebeu muitas críticas tanto do lado militar quanto do lado das ciências ${ }^{26}$, sofrendo dez reformas até 1863, quando o ensino na academia se subdividiu entre a Escola Central e Escola Militar da Praia Vermelha. Embora seu conteúdo tenha se mantido bastante estável no período ${ }^{27}$, mudanças estruturais indicam um processo de diferenciação entre o ensino militar e civil. Na proposta de 1863, uma escola preparatória de dois anos havia aparecido e os estudantes da Escola militar tinham agora que ficar aquartelados na Praia vermelha, separados dos engenheiros à paisana que estudavam no centro da cidade, o que reforçou a distância entre militares e civis, culminando na separação completa dos ensinos militar e civil em $1874^{28}$.

\section{CURRÍCULO DAS ESCOLAS PREPARATÓRIAS, 1863 (dois anos).}

Gramática portuguesa e francesa; tradução e exercícios desta língua; história e geografia, especialmente as do Brasil, aritmética, álgebra elementar, geometria, trigonometria plana, desenho linear e geometria prática; administração de companhia e dos corpos. 


\section{Primeiro Ano}

Primeira Cadeira: Álgebra Superior, Geometria Analítica.

Segunda Cadeira: Física Experimental, Noções de Mecânica, Química Inorgânica e suas aplicações à Pirotecnia; aula de Desenho Topográfico, Topografia e reconhecimento do terreno.

\section{Segundo Ano}

Primeira Cadeira: Tática, Estratégia, Castrametação, História Militar, Fortificação Passageira, noções de Fortificação Permanente, noções de Balística.

Segunda Cadeira: Direito das Gentes, noções de Direito Natural e de Direito Público, Legislação Militar; aula de Desenho de Projeções, Geometria Descritiva.

\section{Terceiro Ano}

Primeira Cadeira: Cálculo Diferencial e Integral, Mecânica, Balística teórica e aplicada.

Segunda Cadeira: Tecnologia Militar, Artilharia, Sistema de fortificação permanente, Ataque e Defesa de praças, Minas Militares; aula de Desenho de fortificação e de máquinas de guerra.

\section{CURRÍCULO DA ESCOLA CENTRAL, 1863}

\section{Primeiro Ano}

Cadeira: Álgebra elementar e superior. Geometria. Trigonometria Retilínea e Esférica.

Aula: Desenho linear e topográfico: noções de topografia.

\section{Segundo Ano}

Primeira Cadeira: Geometria analítica. Teoria geral das projeções. Elementos de cálculo diferencial e integral. A parte da mecânica que só precise daqueles elementos.

Segunda Cadeira: Física experimental, precedendo as noções indispensáveis de mecânica.

Aula: Resolução gráfica dos problemas de geometria descritiva e de suas aplicações à teoria das sombras.

\section{Terceiro Ano}

Primeira Cadeira: Continuação do cálculo diferencial e integral, e da mecânica.

Segunda Cadeira: Química inorgânica e análise respectiva.

Aula: Desenho de máquinas.

\section{Quarto Ano}

Primeira Cadeira: Astronomia. Topografia e Geodésia.

Segunda Cadeira: Botânica e Zoologia, procedendo as noções indispensáveis de química orgânica.

Aula: Desenho geográfico.

\section{Quinto Ano}

Primeira Cadeira: Mecânica aplicada às construções: princípios de arquitetura civil, especialmente quanto à disposição e distribuição dos edifícios; propriedades e resistências dos materiais de construção; noções teóricas e práticas sobre o regímen dos rios e o movimento das águas nos canais e encanamentos; navegação interior, natural e artificial; estradas, pontes, vias férreas e telégrafos.

Segunda Cadeira: Mineralogia e geologia.

Aula: Desenho de arquitetura: ordenação e decoração dos edifícios civis e militares; execução e projeto.

\section{Sexto Ano}

Primeira Cadeira: Estudo complementar da hidrodinâmica aplicada, e dos caminhos de ferro. Descrição e estabelecimento dos motores e máquinas hidráulicas; melhoramento dos rios, relativamente à navegação e às inundações; detalhes de construção dos canais navegáveis; encanamento e derivação de águas; abertura de poços artesianos; obras concernentes à segurança e conservação dos portos; desobstrução das barras e ancoradouros.

Segunda Cadeira: Economia política; estatística e princípios de direito administrativo.

Aula: Desenho de construções e de máquinas hidráulicas. 
No currículo da Praia Vermelha, foram adicionadas aulas de química inorgânica destinadas à pirotecnia, história militar e de direito militar. Na central, aparecem as aulas de química e astronomia, e a história natural dá lugar à zoologia e à botânica. Os dois últimos anos parecem totalmente voltados às tarefas de engenharia: vê-se um maior detalhamento na parte de hidrodinâmica, aulas sobre toda sorte de construções (barragens, portos, poços, canais, edifícios e vias férreas), aulas sobre telégrafos, e uma última cadeira dedicada à economia política, estatística e direito administrativo. Segundo Maria Letícia Corrêa, a disciplina de economia política tinha por objetivo tornar aptos os engenheiros na administração das diversas empresas envolvidas com a "construção das estradas de ferro, os serviços urbanos de transporte e saneamento, as obras públicas e as indústrias" ${ }^{29}$, as marcas da modernização do Brasil de então.

É uma proposta razoavelmente clara de engenharia como profissão, que arregimenta muito mais alunos que na primeira metade do século XIX (Ver Figura 1). A depender dos anos cursados, era possível formar-se em engenheiro geógrafo (os quatro primeiros anos), militar do estado-maior de 1a classe, engenheiro civil (os seis anos da Central), bacharel em ciências matemáticas e físicas (os três primeiros anos de qualquer uma das escolas, mais o quarto ano da Central e a cadeira de Mineralogia e geologia do $5^{\circ}$ ano). 0 bacharelado em ciências matemáticas e físicas parece funcionar como um estágio preparatório, intermediário, menor para a formação final de engenheiro. Estamos às voltas com uma dissociação da engenharia e da matemática, com uma posterior desvalorização das matemáticas em relação à engenharia, e das ciências exatas em relação ao direito e a medicina.

\section{Figura 1: Número de formandos da Escola Politécnica do Rio de Janeiro (1875-1900)}

90

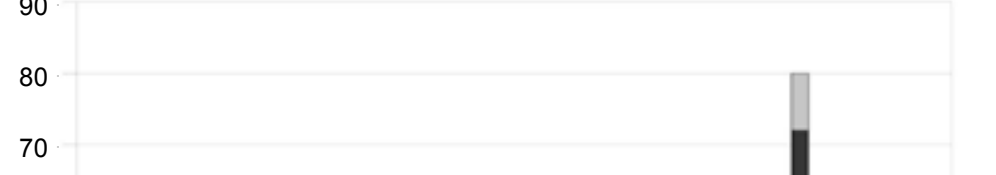

60

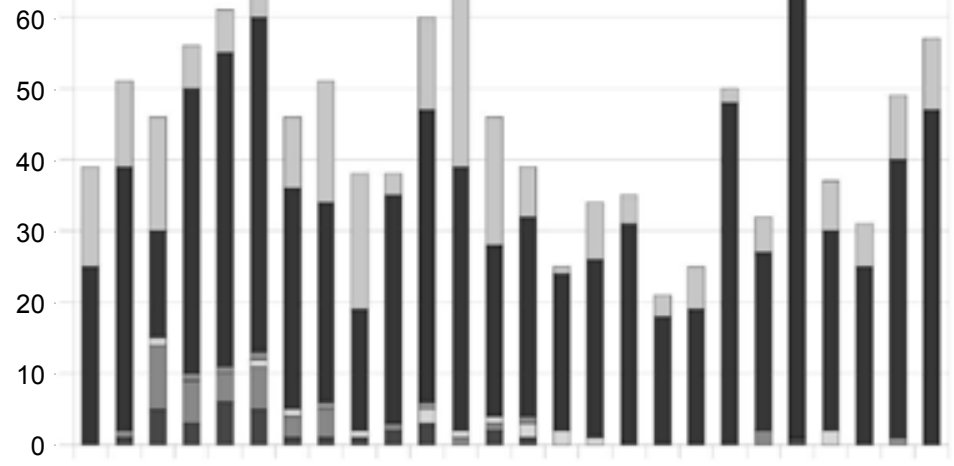

1876187818801882188418861888189018921894189618981900 1875187718791881188318851887188918911893189518971899 $\square$ Engenheiros geógrafos

angenharia civil

ainas

$\square$ Artes e Manufacturas

a Sciencias Physicas e naturaes

- Sciencias Physicas e mathematicas

A Escola de Minas, fundada em 1876, em pleno segundo reinado é um exemplo importante para pensarmos como a matemática começa a deixar de ser fator fundamental na formação dos formandos das escolas de engenharia no último quarto do XIX. 0 decreto 6026 de 1875 é bastante claro quanto aos conteúdos que os Engenheiros de Minas deveriam aprender em seus dois anos de estudo. No que concerne às matemáticas, ele aprenderia "Trigonometria espherica, geometria analytica, complementos de algebra, mecanica; Geometria descriptiva, trabalhos graphicos, desenho de imitação" ${ }^{30}$. Se voltamos aos currículos da Escola Central, a diferença é gritante. Segundo a historiografia, essa organização é decorrente de um misto da École Normale Supérieure, a École de Saint-Étienne e, mais à frente, da École des Mines de Paris, implantado por seu fundador Henri Gorceix ${ }^{31}$. Mas o que é importante é essa relação distinta e desigual entre a matemática e os trabalhos de engenharia práticos: os salários na Escola de Minas também são condizentes com essa condição marginal da matemática. No final do regimento, vemos que 0 
professor adjunto de geometria tinha um salário (6:000\$00) muito próximo dos repetidores (4:000\$00), enquanto que 0 professor de exploração das minas recebia quase o dobro (10:000\$00).

Vinte anos mais tarde, na ocasião do $25^{\circ}$ aniversário do Instituto Politéchnico Brazileiro, em 1888, o engenheiro e secretário do Instituto Paula Freitas dirá:

\begin{abstract}
Senhores! A educação fundada nos preceitos das sciencias exatas é a verdadeira educação scientífica [...]. As matemáticas semeiam a vida em todos os serviços públicos; a indústria lhes deve todo o seu progresso; e nem se pode contestar a feliz influência, que lhes é devida em face dos factos, que têm ocorrido recentemente, e mudando as relações comerciais do mundo inteiro. Que o attestem os engenhosos methodos de cálculo, fornecendo os instrumentos admiráveis, sem os quaes ignoraríamos ainda a sublime instituição da mecânica racional, d'esta sciencia que, assim como nos revela todos os movimentos do universo, nos transmite todas as leis, que o regem, e os mystérios de sua organização, assim também grava nos annaes das nações as bases de todos os progressos relativos à riqueza geral ${ }^{32}$.
\end{abstract}

Isso não significa, portanto, que uma separação entre engenharia e as matemáticas está em curso, mas um protagonismo da primeira sobre a segunda. Os engenheiros do período considerarão o domínio da matemática uma qualidade importante da sua formação, a ferramenta ideal para o trabalho no serviço público e na indústria, mas uma minoria requererá o título de bacharel em Ciências físicas e matemáticas no último quarto do XIX.

A questão da desvalorização deve ser inserida em uma discussão mais ampla: Seriam as reclamações dos engenheiros no final do XIX, a da falta de interesse nas ciências puras nas décadas finais no XIX, uma das facetas do declínio da ilustração brasileira? Para Maria Odila Dias ${ }^{33}$, a ilustração adentraria o segundo reinado. Para José Murilo de Carvalho ${ }^{34}$, improvável que ela durasse tanto, sendo o processo de então uma retomada. Seja como for, após essa diferenciação, os altos quadros imperiais passam a ser compostos por indivíduos oriundos das escolas de direito brasileiras, alijando os engenheiros dos processos decisórios do governo (Tabela 1).

0 discurso de Paula Freitas, em 1888, deve ser visto também como defesa de uma categoria profissional em ascensão. A respeito disto, Luiz Otávio Ferreira ${ }^{35}$ vê a defesa de uma elite técnico-científica que deve, para esses engenheiros, "substituir gradualmente a dos bacharéis, que a própria evolução social tornou obsoleta. A modernização depende da substituição da elite já decadente por outra elite vigorosa" ${ }^{\prime \prime 3}$.

Tabela 1: Tipo de Formação dos Ministros por Períodos - 1822/188937

\begin{tabular}{l|r|r|r|r|r|r|}
\hline Formação & \multicolumn{7}{|c|}{ Períodos } & & Total \\
& $1822 / 31$ & $1831 / 40$ & $1840 / 53$ & $1853 / 71$ & $1871 / 89$ & 72,50 \\
\hline Direito & 51,29 & 56,67 & 85,00 & 77,09 & 85,73 & 7 \\
\hline Ciências Exatas & 20,51 & 13,33 & 5,00 & 2,08 & 0,00 & 16,50 \\
\hline Militar & 28,20 & 20,01 & 10,00 & 18,75 & 7,93 & 3,50 \\
\hline Medicina & 0,00 & 6,66 & 0,00 & 2,08 & 6,34 & 0,50 \\
\hline Religiosa & 0,00 & 3,33 & 0,00 & 0,00 & 0,00 & 100,00 \\
\hline Total & 100,00 & 100,00 & 100,00 & 100,00 & 100,00 & $\mathrm{~N}=200$ \\
\hline
\end{tabular}

Aos poucos, engenheiros e higienistas vão ocupando um lugar de destaque nos processos de urbanização das principais cidades do Brasil ${ }^{38}$. No final do XIX, já na Primeira República, vemos florescer uma grande quantidade de escolas de engenharia no Brasil: Escola Polytechnica de São Paulo, em 1893; Escola de Engenharia de Porto Alegre, em 1896; Mackenzie College, em 1896; e a Escola Livre de Engenharia em Pernambuco, em 1905. Junto com elas, começam a aparecer também uma série de revistas destinadas à engenharia e às ciências exatas ${ }^{39}$. 


\section{Engenharias e ciências puras na Primeira República}

É neste contexto que devem ser inseridos os discursos em favor das ciências puras no começo do século XX proferidos por Manuel Amoroso Costa. Sua militância é representativa de uma fração de engenheiros que está em franca recusa do papel de engenheiro modernizador da cidade, que exerce atividades de engenharia, mas vive a chegada da modernidade de maneira contraditória.

Analisando os textos editados na Revista Didática da Escola Politécnica do Rio de Janeiro, veremos uma multitude de interesses não necessariamente ligados a questões teóricas. Seguindo a classificação da própria revista, vemos as seguintes áreas com a respectiva quantidade de trabalhos publicados entre 1907 e 1917:

Grupo I (44 artigos, 78\% dos artigos publicados): algebra (1), astronomia (4), Cálculo (6), Geometria (1), Geometria Analytica (1), Geometria descriptiva(8), Mecânica aplicada (3), Mecanica Racional (7), Physica (6), Topographia (7);

Grupo II (12 artigos, 22\% dos artigos publicados): resistência e Estabilidade (2), Portos do Mar (1), Mineralogia e Geologia (3), Machinas (1), Hydraulica (3), Construção (1), Economia Política (1).

No primeiro grupo, encontraremos os engenheiros que reclamam o exercício das ciências desinteressadas: Otto de Alencar, Henri Morize, Felipe dos Santos Reis, Sebastião Sodré da Gama, Ortiz Monteiro, Octacilio Novaes, Theodoro Ramos, Licínio Cardoso, Manoel Amoroso Costa, Allyrio de Mattos, entre outros. No segundo, veremos as áreas nas quais eles não publicaram entre 1907 e 1917.

Essa variedade de temas é característica da produção desses engenheiros no período. Além disso, com exceção das revistas ligadas a Academia Brasileira de Ciências onde aparentemente textos originais e de caráter não didático deveriam ser apresentados, não há um lugar distinto dentro da maioria das revistas do período para a publicação de trabalhos originais de pesquisa. Ao contrário, notas de aula se confundem com artigos supostamente originais, vê-se também trabalhos apresentando aspectos de uma determinada teoria que não foram totalmente elucidados nas aulas, e textos de vulgarização científica.

Essa variedade de emprego dos artigos se dá, às vezes, em um mesmo autor. André Rebouças, por exemplo, apresenta várias demonstrações para o teorema de Pitágoras em um artigo, mas em outra fala das "experiências sobre a resistência dos cimentos de Portland". Henri Morize escreve "Como se prevê o tempo", uma transcrição de uma palestra de divulgação ao Diretório Acadêmico da Poli-RJ, um outro texto de caráter didático para um "Curso de Physica", e um trabalho com aspirações originais sobre o "elemento magnético no Rio de Janeiro".

0 caso de Theodoro Augusto Ramos (1895-1936) me parece exemplar. Ao contrário dos engenheiros nos anos 1870, ele parece estar inserido em uma geração de engenheiros já bastante ligada à elite de estado, que pautará os processos decisórios na Primeira República lançando mão de expertise técnica adquirida nos cursos de engenharia ${ }^{40}$. Nesse sentido, não há novidade alguma no fato de que Theodoro Ramos esteja envolvido em várias questões políticas em todos níveis de governo no decorrer de sua carreira. ${ }^{41}$

Depois de se formar engenheiro na Escola Politécnica do Rio de Janeiro em 1918, ele retorna a São Paulo e, no mesmo ano, torna-se professor da Politécnica de São Paulo. Uma vez professor, trabalhará como engenheiro na área de construção de estradas de ferro e de outras obras de engenharia, alcançando em 1926 o seu primeiro grande cargo no governo, a chefia da Comissão do Saneamento da Capital, dentro da Secretaria da Viação e Obras Públicas coordenada por Gabriel Ribeiro dos Santos ${ }^{42}$.

Três anos mais tarde, em 1930, passa a ser secretário da educação do governo intervencionista de João Alberto Luis de Barros e, por indicação desse mesmo governo, a compor o Conselho nacional de educação do governo Vargas ${ }^{43}$. É prefeito interventor da cidade de São Paulo nos primeiros três meses de 1933, empossado pelo então governador Valdomiro Castilhos de Lima44. Theodoro Ramos parece se valer ao mesmo tempo de sua rede de relações no Rio (0 pai tinha negócios no Rio, tinha sido aluno da Politécnica do Rio) e em São Paulo (por exemplo, como professor da EPSP) 
para ocupar cargos ora favoráveis aos paulistanos ora com ares de emissário do governo federal. Em tempos de grande animosidade entre Getúlio Vargas e o Estado de São Paulo, esse duplo pertencimento é inquietante.

Embora considerada a largo pela historiografia das ciências, é essa trajetória política juntamente com todo o capital científico adquirido nos seus anos de politécnico que permitirá a ele exercer importantes ações de política científica nos anos subsequentes: carta branca da parte da elite paulistana para montar uma comitiva de professores europeus que ocuparão as primeiras cátedras da área das ciências exatas da nova Universidade de São Paulo e, mais tarde em 1934, o primeiro diretor da Faculdade de Filosofia, Ciências e Letras da USP.

Tal militância política e profissional nos leva a considerar os textos mais teóricos produzidos por eles como mais uma das múltiplas tarefas que um engenheiro na primeira república exercia, não como uma concessão de um cientista às tarefas práticas do dia a dia. Parece ser constitutivo da trajetória desses engenheiros essa diversidade de tarefas, e a análise da trajetória ${ }^{45}$ dos outros casos pode ajudar a elucidar essa hipótese. Ajuda também a explicar como foi possível politicamente a constituição dos espaços acadêmicos para atividades de ciência pura nas Universidades de São Paulo e do Brasil. Graças a esse trânsito político, esses agentes puderam opinar e direcionar as negociações de modo a privilegiar essas práticas quando emergiram os projetos de universidade nos anos 30.

Essas particularidades do caso brasileiro devem ser enfatizadas pois, enquanto na Europa (penso especialmente no caso da Alemanha, e nas revistas de Göttingen e Berlim) as fronteiras disciplinares entre engenharia, matemática e física já estavam bastante delimitadas (os matemáticos já tinham uma identidade profissional bem precisa, com atuação distinta dos engenheiros e físicos, publicando de maneira geral em veículos especializados, onde as propagandas permitidas, diferentemente das revistas brasileiras, se restringiam a livros e revistas de pesquisa), no Brasil da Primeira República o fenômeno não se verifica. De outra maneira, seria o início de um lento processo de constituição e de autonomização das ciências matemáticas e físicas, gestado a partir de uma fração de engenheiros politécnicos, que conseguiu construir não só um espaço às ciências que eles queriam praticar mas sua própria história.

\section{Notas e referências bibliográficas}

Rogério Monteiro de Siqueira é professor da Escola de Artes, Ciências e Humanidades da USP. E-mail: rogerms@usp.br

1 Agradeço à FAPESP por financiar a pesquisa que me levou às reflexões que apresento neste texto (Auxílio à Pesquisa 2011/02213-6). Agradeço aos colegas que leram ou me ouviram falar deste texto, gentilmente dando sugestões às minhas ideias: Thomás A. S. Haddad, Maria Letícia Corrêa e Catherine Goldstein.

2 COSTA, Manuel Amoroso. As ideias fundamentais da matemática e outros ensaios. São Paulo: Grijaldo, 1971. SIQUEIRA, Rogério Monteiro de. Purity and resentment in newspapers: the arrival of modern mathematics in Brazil. Circumscribere (São Paulo), v. 8, p. 36-44, 2010.

3 COSTA, op. cit., 1971, p. 151.

4 VERGARA, M., Ciência e modernidade no brasil: a constituição de duas vertentes historiográficas da ciência no século XX, Revista da SBHC, v. 2, n. 1, p. 22-31, jan./ jun. 2004.

5 CASTRO, F. M. A matemática no Brasil. In: AZEVEDO, F. de (org.). As ciências no Brasil. São Paulo: Melhoramentos, 1955, v. 1, p. 41-77; HÖNIG, Chaim S.; GOMIDE, Elza F.. Ciências Matemáticas. In: FERRI, M. G.; MOTOYAMA, S. (org.) História das Ciências Matemáticas no Brasil. São Paulo: EPU \& EDUSP, 1979, v. 1, p. 35-60.

6 CASTRO, op. cit., 1955, p. 64.

7 HÖNIG; GOMIDE, op. cit., 1979, p.43.

8 VIDEIRA, Antonio Augusto Passos. Henrique Morize e o ideal de ciência pura na República Velha. Rio de Janeiro: FGV, 2003.

9 HÖNIG; GOMIDE, op. cit., 1979.

10 SILVA, C. M. A matemática positivista e sua difusão no Brasil. Vitória: EDUSF, 1999. SILVA, C.M. Faculdade de Filosofia, Ciências e Letras da USP e a formação de professores de Matemática. In: 23a REUNIÃO ANUAL DA ANPED, 2001; SILVA, C. M. Formação de professores e pesquisadores de matemática na Faculdade nacional de filosofia. Cadernos de Pesquisa. São Paulo: Fundação Carlos Chagas. n. 117, p. 103-126, nov. 2002; SILVA, C. M. Politécnicos ou matemáticos? História, Ciências, Saúde - Manguinhos, v. 13, n. 4, p. 891-908, 2006; PEREIRA DA SILVA, C. Otto de Alencar Silva versus Auguste Comte. LLULL. Rioja: SEHCYT, v.18, p. 167-181, 1995; PEREIRA DA SILVA, C. A contribuição de Otto de Alencar Silva para o desenvolvimento da ciência no Brasil. Revista da SBHC. Rio de Janeiro: SBHC, n. 19, p. 13-30, 1998; PEREIRA DA SILVA, C. Manuel Amoroso Costa: 0 continuador da obra 
matemática de Otto de Alencar silva. LIull. Rioja: SEHCYT, v. 23, p. 91-101, 2000; D’AMBROSI0, Ubiratan. História da matemática no Brasil: Uma visão panorâmica até 1950. Saber y Tiempo, Buenos Aires: Asociación Biblioteca José Babini, v.2, 8, p. 7-37, 1999; D’AMBROSIO, Ubiratan. Uma história concisa da matemática no Brasil. Petrópolis: Editora Vozes, 2008.

11 SILVA, op. cit., 2006, p. 893.

12 COSTA, op. cit., 1971, p. 75.

13 D'AMBROSIO, op. cit., 2008, p. 50.

14 PEREIRA DA SILVA, 1995, op. cit., p. 169. Sobre a questão do positivismo ser nefasto às ciências matemáticas, apresento algumas críticas em relação a essa tese em: SIQUEIRA, Rogério Monteiro. Reavaliando os debates sobre o positivismo nas ciências matemáticas brasileiras do começo do Século XX. In: 26오 SIMPÓSIO NACIONAL HISTÓRIA. São Paulo: ANPUH, 2011.

15 CASTRO, op. cit., 1955.

16 Dominichi Miranda de Sá caracterizou o momento como o advento do cientista como profissão. Focalizando sua análise nos sanitaristas do período, ela demonstra como o discurso dos cientistas aos poucos foi se diferenciando dos homens de letras. Ver SÁ, Dominichi Miranda de. A Ciência como Profissão: médicos, bacharéis e cientistas no Brasil (1895-1935). Rio de Janeiro: Ed. da Fiocruz, 2006.

17 CARRETA, Jorge Augusto. Os intelectuais e a ideia de universidade no Brasil dos anos 20. 1999. Dissertação (Mestrado) - Instituto de Filosofia e Ciências Humanas. Universidade de Campinas.

18 SARAIVA, Luís Manuel Ribeiro. The beginnings of the Royal military academy of Rio de Janeiro. Revista Brasileira de História da Matemática. Rio Claro: SBHMAT, v. 7, 13, p. 19-41, 2007.

19 DIAS, Maria Odila da Silva. Aspectos da ilustração no Brasil. Revista do IHGB. Rio de Janeiro: IHGB, v. 278, p. 105-170, jan.-mar. 1968.

20 DIAS, 1968, op. cit.

21 DHOMBRES, Jean. Livros. Dando nova forma à ciência. In: DARNTON, R.; ROCHE, D. (Orgs.). Revolução Impressa. A imprensa na França 1775-1800. São Paulo: EDUSP, 1989, p. 237-285.

22 São traduções: os Elementos de geometria, de A. M. Legendre (1809), o Tratado de trigonometria, de A. M. Legendre (1809), da tradução de Manuel Ferreira de Araújo Guimarães; o Tratado elementar d'arithmetica (1810), os Elementos de arithmética (1811) e o Tratado elementar de cálculo diferencial e cálculo integral (1812), todos de Lacroix, traduzidos por Francisco Cordeiro da Silva Torres; o Tratado elementar de physica do Abade Haüy, volume 1 e 2 , possivelmente entre 1810 e 1812, cujo tradutor é desconhecido; os Elementos de álgebra de Leonhard Euler (1811), atualmente sem nenhum exemplar conhecido; o Tratado elementar de aplicação da álgebra à geometria (1812) de Lacroix, traduzido por José Victorino dos Santos e Souza; Os tratados elementares de Mechanica, Dynamica, Hydrostática e Hydrodinâmica, todos traduzidos em 1812 por José Saturnino da Costa Pereira; 0 Tratado de óptica (1813) de Lacaille, atribuído a André Pinto; a Dissertação sobre fortificação permanente sobre a fortificação de campanha, e sobre o alcance de bombas (1814) de M. Hennert, por Joaquim Ignacio de Lima; Complementos dos elementos de álgebra (1813) de Lacroix, cujo tradutor é desconhecido.

São obras de autoria: Variação dos triângulos esphericos (1812), Elementos de astronomia (1814), Elementos de Geodésia (1814), da autoria de Manuel Ferreira de Araújo Guimarães; Elementos de desenho (1817), da autoria de Roberto Ferreira da Silva; Quadro analytico do nosso sistema planetário (1820), da autoria de Joaquim Bento da Fonseca. Cf. CAMARGO, Ana Maria de Almeida. MORAES, Rubens Borba. Bibliografia da Impressão Régia do Rio de Janeiro (1808-1822). São Paulo: Edusp e Livraria Kosmos Editora, 1993.

23 Transcrita por Luís Saraiva. Ver SARAIVA, Luís Manuel Ribeiro. Manoel Ferreira de Araújo Guimarães (1777-1838): From the Navy Royal Academy to the Royal Military Academy of Rio de Janeiro. Revista Brasileira de História da Matemática, v. 11, n. 21, p. 77-106, 2011. p. 102-105.

24 D'AMBROSIO, op. cit., 2004.

25 Um exemplo das ciências naturais é o de José Bonifácio de Andrada e Silva, tutor de D. Pedo II. Cf. VARELA, A. G. ; LOPES, M. M.; FONSECA, M. R. F. da. As atividades do filósofo natural José bonifácio de Andrada e Silva em sua fase portuguesa (1780-1819). História, Ciências, Saúde - Manguinhos, v. 11, n. 3, p. 685-711, set.-dez. 2004.

26 Vale lembrar que o número de alunos nos primeiros vinte anos da academia foi bastante pequeno (Embora em 1811, matricularam-se 74 alunos, em 1817 foram seis; em 1818, três; em 1820, dois; em 1828, três ) e que a entrada na carreira militar até os anos 50 dispensava a passagem pela Academia, a origem familiar pesava bem mais para obter altas patentes, o que parece dar à Academia um papel muito mais de formação de elites do que de profissionais do exército. Cf. SIQUEIRA, Rogério Monteiro de; MORMÊLLO, Ben Hur. A gênese ilustrada da Academia Real Militar e suas onze reformas curriculares (1810-1874). História da Ciência e Ensino: construindo interfaces, v. 3, p. 17-30, 2011.

27 SIQUEIRA; MORMÊLLO, op. cit., 2011.

28 BRASIL. Decreto n. 3.083 de 28 de Abril de 1863, assinado pelo Ministro e secretário de estado dos negócios da guerra Polydoro da Fonseca Quintanilha Jordão.

29 CORRÊA, Maria Letícia. Engenharia, economia política e progresso: a trajetória do engenheiro Luiz Rafael Vieira Souto como estudo de caso (1849-1922). Revista Brasileira de História da Ciência, v. 3, p. 157-169, 2010, p. 164.

30 BRASIL. Decreto n. 6026 de 6 de novembro de 1875, assinado pelo Ministro e Secretário de estado dos Negócios do Império José Bento da Cunha e Figueiredo.

31 CARVAlHO, José Murilo de. A Escola de Minas de Ouro Preto: o peso da glória. Belo Horizonte: Editora UFMG, 2002.

32 FREITAS, Antonio de Paula. Discurso no 250 Aniversário da instalação do Instituto Politécnico Brasileiro. Revista do Instituto Politécnico Brasileiro. Rio de Janeiro: IPB, t. XVIII, p. 25, 1888.

33 DIAS, op. cit., 1968.

34 CARVALHO, op. cit. 2002.

35 FERREIRA, Luiz Otávio. Os Politécnicos: ciência e reorganização social segundo o pensamento positivista da Escola Politécnica do Rio de Janeiro (18621922). 1989. Dissertação (Mestrado) - Universidade Federal do Rio de Janeiro.

36

FERREIRA, op. cit., 1989, p.120. 
38 SÁ, op. cit., 2006; BENCHIMOL, Jaime Larry. Pereira Passos, um Haussmann tropical. A renovação urbana na cidade do Rio de Janeiro no início do Século XX. Rio de Janeiro: Secretaria Municipal de Cultura, Turismo e Esportes, 1992; CESAROLI, Josianne Francia. A grande cruzada: os engenheiros e as engenharias de poder na Primeira República. 1998. Dissertação (Mestrado) - Universidade Estadual de Campinas.

39 PEREIRA DA SILVA, C. Sociedades e Revistas Científicas Fundadas no Brasil entre 1889 e 1989. Revista Uniandrade, Curitiba: Uniandradre, v. 2, n. 3 , 2001.

40 Seu pai, Augusto Ferreira Ramos (1860-1939), engenheiro formado na EPRJ e professor da Escola Politécnica de São Paulo, esteve ligado ao Secretário de Agricultura do estado Carlos José Botelho, em meados de 1904, contribuindo com duas obras influentes sobre a cultura do café no Brasil: 0 café no Brasil e no estrangeiro, 1923; A crise do café, de 1930.

41 Embora isto não prescinda, no futuro, do exercício de esmiuçamento da rede de contatos acionados para colocar Theodoro Ramos nesses espaços governamentais e de um estudo prosopográfico que tome por objeto toda essa geração de engenheiros. A passagem por órgãos públicos e a militância política também é característica de Felipe dos Santos Reis. Ele lecionará na Escola Nacional de Belas Artes a partir de meados dos anos 20. Simultaneamente à carreira de professor, será sócio de uma empresa de encadernação, em 1934, e a partir de 1941 da S.A. Empresa de Força e Luz Ibero-Americana, participando ativamente de seus conselhos diretores e fiscais. Além disso, trabalhará em vários momentos como engenheiro em secretarias públicas ligadas a questões de engenharia. A partir do final dos anos 40, ele será chamado para participar de bancas de concurso por diversas vezes na área de geometria, resistência de materiais e desenho.

42 FARIA, Rodrigo Santos. A engenharia entre a técnica e a política na construção dos (disputa pelos) setores públicos de obras urbanas do estado de São Paulo: 0 caso da Comissão de Obras Novas do Abastecimento de Águas da Capital (1926-1927). Politeia: História e sociedade. Vitória da Conquista: UESB, v. 9, n.1, p.173-195, 2009 .

43 MICELI, Sergio. 0 Conselho nacional de educação: esboço de análise de um aparelho de estado (1931-1937). In: MICELI, Sergio. Intelectuais à brasileira. São Paulo: Cia das Letras, 2001, p. 295-341.

44 SÃO PAULO (Brasil). Diário oficial de São Paulo, Quinta-feira, 2 de Julho de 1936, n. 146, p. 16.

45 No sentido proposto por Bourdieu, em A ilusão biográfica, "como série de posições ocupadas por um mesmo agente (ou um mesmo grupo) num espaço que é ele próprio um devir, estando sujeito a incessantes transformações". Cf. BOURDIEU, Pierre. A ilusão biográfica. In: BOURDIEU, Pierre. Razões práticas: sobre a teoria da ação. Campinas, SP: Papirus, 1996, p. 74-82.

[Recebido em Março de 2013. Aceito para publicação em Março de 2014] 